\title{
Schnell härtendes Dichtungsmaterial
}

Speziell für die Abdichtung von Komponenten aus inaktiven Werkstoffen wie Edelstahl hat Hernon Manufacturing Inc., in Deutschland vertreten durch die Firma 4 Advanced Technologies, ein anaerobes Dichtungsmaterial entwickelt. Bei Verwendung dieses Materials mit dem Namen Dripstop 940 erübrigt sich der sonst übliche Einsatz eines Aktivators. Der Dichtstoff besitzt eine UL-Zulassung und eine Freigabe für DEF-Systeme nach ISO 22241-2 (Abgasnachbehandlung), sodass er auch für Erdgas-, Öl-, Diesel- und Benzinleitungen in Kraftfahrzeugen eingesetzt werden kann.

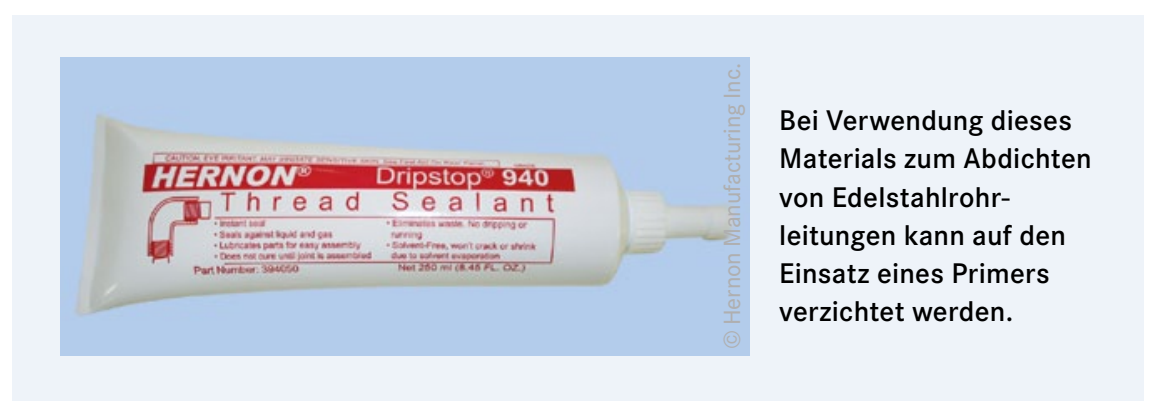

Das chemisch träge Dichtungsmaterial hält Drücken (Gas und Flüssigkeiten) bis 250 psi und Temperaturen bis $204^{\circ} \mathrm{C}$ stand, besteht aus nur einer Komponente, ist lösungsmittelfrei, tropft und verläuft nicht. Außerdem bricht und schrumpft es nicht während des Aushärtens. Die Demontage damit abgedichteter Komponenten ist ebenfalls möglich.

Weiterelnfos: www.4advancedtechnologies.de

\section{Schutzbeschichtung mit dualem Härtungskonzept}

Q peziell für Anwendungen, bei denen Schattenzonen zu Problemen bei der Aushärtung führen können, empfiehlt sich im Bereich der Leiterplattenfertigung der Einsatz der von Dymax entwickelten Schutzbeschichtung Dual-Cure 9482, die mit Licht- und Feuchtigkeit aushärtet. Dabei handelt es sich um lösemittelfreies Material, das an der Oberfläche mit UV-Licht und unterhalb der Komponenten im Laufe der Zeit mit

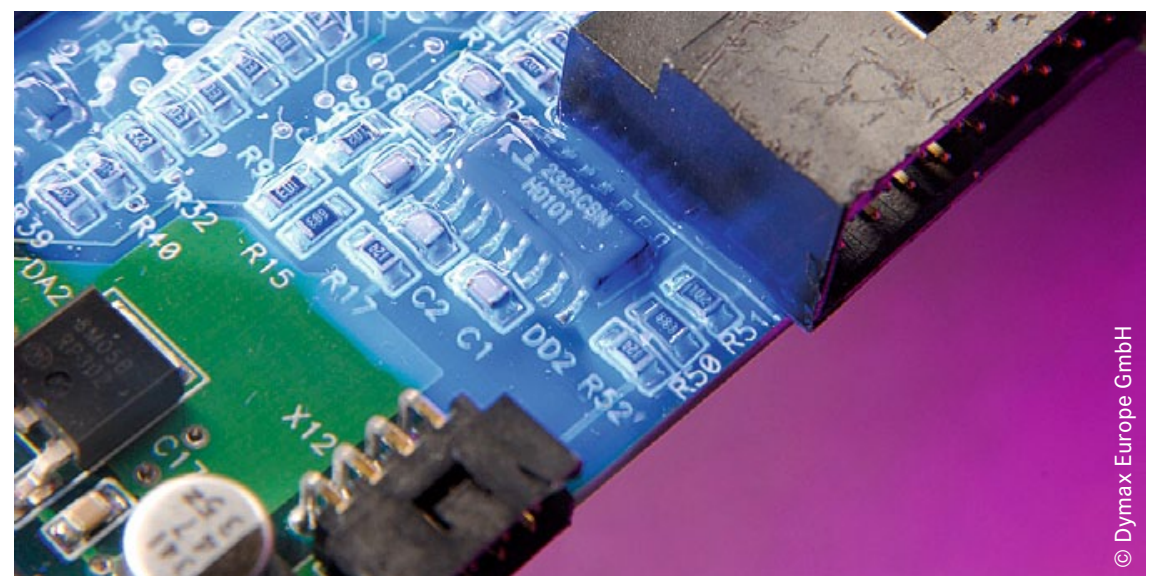

Für die Leiterplattenfertigung steht eine lösemittelfreie Schutzbeschichtung zur Verfügung, die mit Licht bzw. in Schattenbereichen durch die Umgebungsfeuchtigkeit aushärtet.
Umgebungsfeuchtigkeit aushärtet. Die benötigte Verarbeitungszeit ist deutlich niedriger als bei lösemittelbasierten Produkten oder thermischen Beschichtungen. Dies ermöglicht eine schnellere Produktion, höhere Durchsatzraten und somit eine Senkung der jährlichen Produktionskosten.

Die Aushärtung mit Umgebungsfeuchtigkeit in Schattenzonen eliminiert die Notwendigkeit weiterer Ver- 